\title{
Prevalence of antibodies to swine influenza viruses in humans with occupational exposure to pigs, Thuringia, Germany, 2008-2009
}

\begin{tabular}{|c|c|}
\hline Journal: & Journal of Medical Virology \\
\hline Manuscript ID: & JMV-09-1647.R2 \\
\hline Wiley - Manuscript type: & Research Article \\
\hline $\begin{array}{r}\text { Date Submitted by the } \\
\text { Author: }\end{array}$ & 28-Apr-2010 \\
\hline Complete List of Authors: & $\begin{array}{l}\text { Krumbholz, Andi; Jena University Hospital, Dept. of Virology and } \\
\text { Antiviral Therapy } \\
\text { Lange, Jeannette; Jena University Hospital, Dept. of Virology and } \\
\text { Antiviral Therapy } \\
\text { Dürrwald, Ralf; IDT Biologika GmbH, Dept. Research and } \\
\text { Development } \\
\text { Hoyer, Heike; Jena University Hospital, Dept. of Medical Statistics } \\
\text { and Documentation } \\
\text { Bengsch, Stefan; Jena University Hospital, Dept. of Transfusion } \\
\text { Medicine } \\
\text { Wutzler, Peter; Jena University Hospital, Dept. of Virology and } \\
\text { Antiviral Therapy } \\
\text { Zell, Roland; Friedrich Schiller University, Institut of Virology and } \\
\text { Antiviral Therapy }\end{array}$ \\
\hline Keywords: & $\begin{array}{l}\text { porcine influenza virus, zoonotic infection, virus neutralisation } \\
\text { assay, hemagglutination-inhibition assay, occupational exposure }\end{array}$ \\
\hline
\end{tabular}

\section{(s) ScholaroNE \\ Manuscript Central}


TABLE I. Composition of Study and Control Groups

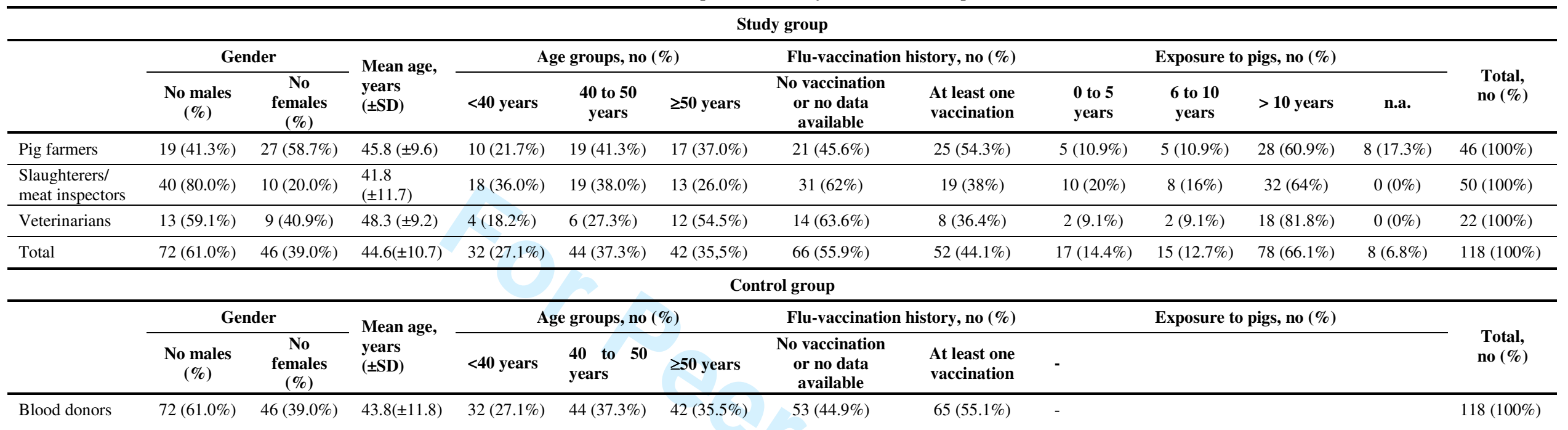


TABLE II. Antibody Titers of Proband and Control Sera Conspicuous in HI Assay*

2 5 Serum Gender Age, Flu vaccination Time of pig exposition, Reciprocal geometric mean titers of hemagglutination inhibition (HI) and neutralisation tests (NT)

7 S

$8 \mathrm{~S}$

9 S8

$10 \mathrm{~s} 12$

11 s2

12 s22

13 s24

14 S47

15 PF16

16 PF18

17 PF22

18 PF4

19 PF44

$20 \mathrm{~V} 1$

$21 \mathrm{~V} 8$

$22 \mathrm{~V} 10$

$23 \vee 14$

$24 \mathrm{~V} 18$

$25 \mathrm{C} 7$

$26 \mathrm{C} 10$

$27 \mathrm{C} 24$

$28 \mathrm{C} 29$

$29 \mathrm{C} 64$

$30 \mathrm{C} 78$

$31 \mathrm{C} 86$

$\mathrm{C} 88$

$32 \mathrm{C} 88$

33 C115

34

35

$\begin{array}{ll}\text { annual vacc. } & 1.5 \\ \text { no vaccination } & 20\end{array}$

huH1N1 $^{2}$

swH1N2 $^{3}$

huH1N2 ${ }^{4}$

SwH3N2 ${ }^{5}$

huH3N2 ${ }^{6}$

no vaccination

1 vaccination

1 vaccination

no vaccination

no vaccination

no vaccination

1 vaccination

annual vacc.

no vaccination

1 vaccination

annual vacc.

annual vacc.

annual vacc.

no vaccination

no vaccination

1 vaccination

no vaccination

annual vacc.

no vaccination

at least 2 vacc.

ast 2 vacc.

no vaccination

1 vaccination

no vaccination

at least 2 vacc.

at least 2 vacc.

HAHT

NT HAHT

NT HAHT

NT HAHT

NT

NT

HAHT

NT

$\begin{array}{lllllllllllll}1.5 & 3.79 & <20 & 80.00 & 40.00 & 160.00 & 40.00 & 80.00 & <20 & 29.39 & <20 & 160.00 & <20 \\ 20 & 20.00 & 26.26 & 9.28 & <20 & 34.29 & 28.28 & 50.40 & 20.00 & 80.00 & 2031.87 & 63.50 & 56.57 \\ 33 & 29.39 & 20.00 & - & - & 65.63 & 20.00 & - & - & 226.27 & 89.80 & - & -\end{array}$

37 sera with HI titers $\geq 80$ or 4-fold increase of $\mathrm{Hl}$ titer relative to group-specific mean titers

$38{ }^{2}$ huH1N1 strain: A/New Caledonia/20/1999

$39^{3}$ swH1N2 strains: A/swine/Bakum/1832/2000, A/swine/Waltersdorf/IDT2527/2003, A/swine/Gudensberg/IDT2930/2004

$40_{5}^{4}$ huH1N2 strain: A/Baden Württemberg/20/2003

$40{ }_{5}$ swH3N2 strains: A/swine/Bakum/1769/2003, A/swine/Bissendorf/IDT1864/2003, A/swine/Herzlake/IDT5336/2006

416 huH3N2 strain: A/Berlin/1/2003

42

43 
TABLE III. Summary of HI Assays

\begin{tabular}{|c|c|c|c|c|c|c|}
\hline \multirow[b]{3}{*}{ Virus } & \multirow[b]{3}{*}{ Titer } & \multicolumn{5}{|c|}{ Number of sera } \\
\hline & & \multicolumn{4}{|c|}{ Study group $(n=118)$} & \multirow{2}{*}{$\begin{array}{l}\text { Control group } \\
\quad(n=118)\end{array}$} \\
\hline & & Slaughterers $(\mathbf{n}=\mathbf{5 0})$ & Pig farmers $(n=46)$ & Veterinarians $(n=22)$ & Total $(n=118)$ & \\
\hline \multirow[t]{4}{*}{ swH1N1 } & $<20$ & 35 & 19 & 19 & 84 & 104 \\
\hline & 20 to $<40$ & 13 & 3 & 3 & 32 & 14 \\
\hline & 40 to $<80$ & 2 & - & - & 2 & - \\
\hline & $\geq 80$ & - & - & - & - & - \\
\hline \multirow[t]{4}{*}{ swH1N2 } & $<20$ & 14 & 7 & 3 & 24 & 32 \\
\hline & 20 to $<40$ & 20 & 31 & 15 & 66 & 54 \\
\hline & 40 to $<80$ & 14 & 6 & 2 & 22 & 25 \\
\hline & $\geq 80$ & 2 & 2 & 2 & 6 & 7 \\
\hline \multirow[t]{4}{*}{ swH3N2 } & $<20$ & 23 & 13 & 10 & 46 & 46 \\
\hline & 20 to $<40$ & 13 & 29 & 5 & 47 & 38 \\
\hline & 40 to $<80$ & 9 & 1 & 4 & 14 & 29 \\
\hline & $\geq 80$ & 5 & 3 & 3 & 11 & 5 \\
\hline \multirow[t]{4}{*}{ huH1N1* } & $<20$ & 8 & 5 & - & 13 & 18 \\
\hline & 20 to $<40$ & 29 & 30 & 16 & 75 & 54 \\
\hline & 40 to $<80$ & 4 & 3 & 4 & 11 & 22 \\
\hline & $\geq 80$ & 8 & 8 & 2 & 18 & 24 \\
\hline \multirow[t]{4}{*}{ huH1N2* } & $<20$ & - & 4 & 7 & 11 & 24 \\
\hline & 20 to $<40$ & 16 & 17 & 10 & 43 & 52 \\
\hline & 40 to $<80$ & 20 & 18 & 4 & 42 & 20 \\
\hline & $\geq 80$ & 13 & 7 & 1 & 21 & 22 \\
\hline \multirow[t]{4}{*}{ huH3N2* } & $<20$ & 3 & 2 & - & 5 & 8 \\
\hline & 20 to $<40$ & 16 & 12 & 11 & 39 & 56 \\
\hline & 40 to $<80$ & 11 & 8 & 6 & 25 & 23 \\
\hline & $\geq 80$ & 19 & 24 & 5 & 48 & 31 \\
\hline A/Port Chalmers/1/73 & $<20$ & 1 & 2 & 1 & 4 & 1 \\
\hline \multirow[t]{3}{*}{$(\mathrm{H} 3 \mathrm{~N} 2)^{*}$} & 20 to $<40$ & 26 & 23 & 10 & 59 & 54 \\
\hline & 40 to $<80$ & 11 & 14 & 2 & 27 & 36 \\
\hline & $\geq 80$ & 11 & 7 & 9 & 27 & 27 \\
\hline \multirow[t]{4}{*}{ A/Chile/1/83 (H1N1)* } & $<20$ & - & 6 & 2 & 8 & 6 \\
\hline & 20 to $<40$ & 33 & 27 & 15 & 75 & 88 \\
\hline & 40 to $<80$ & 14 & 12 & 3 & 29 & 18 \\
\hline & $\geq 80$ & 2 & 1 & 2 & 5 & 6 \\
\hline \multicolumn{7}{|c|}{ * Study group comprised 117 sera } \\
\hline \multicolumn{7}{|c|}{ John Wiley \& Sons } \\
\hline
\end{tabular}


TABLE IV. Prevalences of Antibodies Against Porcine Influenza Viruses

\begin{tabular}{|c|c|c|c|c|c|c|}
\hline \multirow[b]{2}{*}{ Group } & \multicolumn{2}{|c|}{ H1N1 } & \multicolumn{2}{|c|}{ H1N2 } & \multicolumn{2}{|c|}{ H3N2 } \\
\hline & $\begin{array}{c}\text { Prevalence } \\
\text { (no., \%) }\end{array}$ & $\begin{array}{c}\text { 95\% CI (\%), } \\
\text { p-value** }\end{array}$ & $\begin{array}{l}\text { Prevalence } \\
\text { (no., \%) }\end{array}$ & $\begin{array}{c}\text { 95\% CI (\%), } \\
\text { p-value* }\end{array}$ & $\begin{array}{l}\text { Prevalence } \\
\text { (no., \%) }\end{array}$ & $\begin{array}{c}\text { 95\% CI (\%), } \\
\text { p-value* }\end{array}$ \\
\hline $\begin{array}{l}\text { Slaughterers } \\
(n=50)\end{array}$ & $\begin{array}{l}2 \text { of } 50 \\
4.0\end{array}$ & $\begin{array}{l}(0.4,13.8), \\
-\end{array}$ & $\begin{array}{l}3 \text { of } 50 \\
6.0\end{array}$ & $\begin{array}{l}(1.2,16.6) \\
0.025\end{array}$ & $\begin{array}{l}7 \text { of } 50 \\
14.0\end{array}$ & $\begin{array}{l}(5.8,26.8) \\
<0.001\end{array}$ \\
\hline $\begin{array}{l}\text { Pig farmers } \\
(n=46)\end{array}$ & $\begin{array}{l}0 \text { of } 46 \\
0.0\end{array}$ & $\begin{array}{l}(0.0,7.8), \\
-\end{array}$ & $\begin{array}{l}2 \text { of } 46, \\
4.3\end{array}$ & $\begin{array}{l}(0.5,14.9), \\
0.077\end{array}$ & $\begin{array}{l}4 \text { of } 46 \\
8.7\end{array}$ & $\begin{array}{l}(2.4,20.8) \\
0.006\end{array}$ \\
\hline $\begin{array}{l}\text { Veterinarians } \\
(n=22)\end{array}$ & $\begin{array}{l}0 \text { of } 22, \\
0.0\end{array}$ & $\begin{array}{l}(0.0,15.5), \\
-\end{array}$ & $\begin{array}{l}2 \text { of } 22, \\
9.1\end{array}$ & $\begin{array}{l}(1.1,29.2) \text {, } \\
0.024\end{array}$ & $\begin{array}{l}5 \text { of } 22, \\
22.7\end{array}$ & $\begin{array}{l}(7.8,45.4) \\
<0.001\end{array}$ \\
\hline $\begin{array}{l}\text { Exposed group } \\
(\mathrm{n}=118)\end{array}$ & $\begin{array}{l}2 \text { of } 118, \\
1.7\end{array}$ & $\begin{array}{l}(0.0,6.0), \\
-\end{array}$ & $\begin{array}{l}7 \text { of } 118, \\
5.9\end{array}$ & $\begin{array}{l}(2.4,11.9) \\
0.01\end{array}$ & $\begin{array}{l}16 \text { of } 118, \\
13.6\end{array}$ & $\begin{array}{l}(7.9,21.1) \\
<0.001\end{array}$ \\
\hline $\begin{array}{l}\text { Control group } \\
(\mathrm{n}=118)\end{array}$ & $\begin{array}{l}0 \text { of } 118 \\
0.0\end{array}$ & $(0.0,3.1)$ & $\begin{array}{l}0 \text { of } 118, \\
0.0\end{array}$ & $(0.0,3.1)$ & $\begin{array}{l}0 \text { of } 118 \\
0.0\end{array}$ & $\begin{array}{l}(0.0,3.1) \\
-\end{array}$ \\
\hline
\end{tabular}

$*$ p-values of exact $\chi^{2}$-test, exposed subgroup compared to control 

with Occupational Exposure to Pigs, Thuringia, Germany, 2008-2009

\author{
Andi Krumbholz ${ }^{1}$, \\ Jeannette Lange ${ }^{1}$, \\ Ralf Dürrwald ${ }^{2}$, \\ Heike Hoyer ${ }^{3}$, \\ Stefan Bengsch ${ }^{4}$, \\ Peter Wutzler ${ }^{1}$, \\ Roland Zell ${ }^{1} *$
}

${ }^{1}$ Institut für Virologie und Antivirale Therapie, Universitätsklinikum Jena, Germany

${ }^{2}$ IDT Biologika GmbH, Dessau-Rosslau, Germany

${ }^{3}$ Institut für Medizinische Statistik und Dokumentation, Universitätsklinikum Jena, Germany

${ }^{4}$ Institut für Transfusionsmedizin, Universitätsklinikum Jena, Germany

running title: Prevalence of antibodies to swine influenza viruses in exposed humans

* Correspondence to: Roland Zell, PhD

Institut für Virologie und Antivirale Therapie

Hans Knöll Str. 2

D-07745 Jena

Germany

phone: +49 36419395721

fax: +49 3641939732

Roland.Zell@med.uni-jena.de 


\begin{abstract}
The Eurasian lineages of swine influenza viruses are different genetically from classical swine H1N1 influenza viruses and comprise avian-like H1N1 and human-like H1N2 and H3N2 subtypes. Although sporadic isolation of such viruses from human specimens has been reported, the prevalence of human infections is not known. In the present study, the seroprevalence against Eurasian swine influenza viruses was investigated. Sera were collected in Thuringia, Germany, from December 2007 to April 2009. The study group comprised 118 professionals with occupational exposure to pigs (50 pig slaughterers/meat inspectors, 46 pig farmers, 22 veterinarians caring for pig herds). The control group included 118 age- and gender-matched blood donors from Thuringia. As a result, 18 sera of the study group were identified with raised hemagglutination-inhibition titers against a panel of nine swine influenza viruses (three strains/subtype). For 17/18 sera this finding was confirmed in the neutralisation assay. For 11/18 sera the raise of titers was significant, i.e., a fourfold increase of hemagglutinationinhibition titers was observed. No gender-specific bias of the high titer sera was observed. Twelve sera of the control group showed increased hemagglutination-inhibition titers against swine influenza viruses. Hemagglutination-inhibition titers of 2/12 control sera were raised fourfold but did not exhibit a significant increase of neutralisation titers. All increased hemagglutination-inhibition titers of the control group may be explained by cross-reactivity with seasonal influenza virus strains, as all these sera also reacted with human strains.
\end{abstract}

Keywords: porcine influenza virus, zoonotic infection, virus neutralisation assay, hemagglutinationinhibition assay, occupational exposure 


\section{INTRODUCTION}

Influenza A virus (FLUAV) of the genus Influenza virus A, family Orthomyxoviridae, is an important human and animal pathogen. The FLUAV host spectrum includes birds, pigs, humans and some other mammalian species. Sixteen hemagglutinin (HA) and nine neuraminidase (NA) genes allow the formation of up to 144 different subtypes, of which at least 110 have been described in aquatic birds, the main reservoir hosts. FLUAVs circulating in humans comprise the H1N1 and H3N2 subtypes and are the causative agents of seasonal influenza. Apart from seasonal influenza, occasional zoonotic infections of humans occur. Such infections may have a great impact on human health and bear the potential of a pandemic. Infections of humans with highly pathogenic avian H5N1 influenza viruses [Peiris et al., 2004; Subbarao et al., 1998] or a new pandemic swine-origin H1N1 influenza virus [Centers for Disease Control and Prevention, 2009; Novel Swine-Origin Influenza A (H1N1) Virus investigation Team, 2009] may serve as recent examples. Swine-to-human transmissions of classical swine H1N1 influenza viruses were first observed in Czechoslovakia in the 1950s [Kluska et al., 1961]. Since then, sporadic infections were demonstrated repeatedly by virus isolation in the United States, Europe and the Asian part of the former Soviet Union [reviewed in Myers et al., 2007]. After 1997, novel triple reassortant swine influenza viruses of the $\mathrm{H} 3 \mathrm{~N} 2, \mathrm{H} 1 \mathrm{~N} 2, \mathrm{H} 2 \mathrm{~N} 3, \mathrm{H} 3 \mathrm{~N} 1$, and $\mathrm{H} 1 \mathrm{~N} 1$ subtypes emerged in the pig population of the USA and Canada with gene segments of classical swine, avian and human viruses [Olsen, 2002]. Recently, several of these reassortants have been isolated from human patients [Shinde et al. 2009].

Eurasian swine influenza A viruses (swFLUAVs) belong to genetic lineages different from the American swFLUAVs. In Europe, porcine H1N1 strains isolated since 1979 are 'avian-like' as all segments derived from an avian virus [Pensaert et al., 1981; Witte et al., 1981]. In 1984, reassortment of an avian-like H1N1 swFLUAV and a human A/Port Chalmers/1/73-like virus yielded a so-called 'human-like' swine H3N2 strain with the HA and NA genes originating from the human virus and all segments encoding the internal proteins still being avian-like [Castrucci et al., 1993]. Furthermore, a 'human-like' swine H1N2 triple reassortant emerged in 1994 after reassortment of an European 
swFLUAV with human H1N1 and H3N2 strains [Brown et al., 1995]. Although European swFLUAVs and reassortant progeny strains also emerged in Hong Kong [Gregory et al., 2003; Smith et al., 2009] and other Asian countries [Komadina et al., 2007], they became prevalent only in the European pig population. There, they replaced the former classical swine strains. Seven cases of human infection with the Eurasian H1N1 and H3N2 swFLUAVs have been reported so far [Adiego Sancho et al., 2009; Claas et al., 1994; Gregory et al., 2001; Gregory et al. 2003; Rimmelzwaan et al., 2001; Schweiger et al., 2008].

Recently, novel genotypes of zoonotic swFLUAVs emerged after reassortment of Eurasian and North American swFLUAVs: (i) Strains isolated in Thailand and the Philippines demonstrate the reassortment of classical swine viruses or North American triple reassortants (HA donor) with Eurasian H1N1, H1N2 and H3N2 swFLUAVs (donor of NA and internal genes) [Chutinimitkul et al., 2008; Komadina et al., 2007]. (ii) Another novel genotype, which emerged in Mexico, comprises the PB2, PB1, PA, HA, NP and NS segments of a North American triple reassortant and the NA and MP segments of an Eurasian swFLUAV [Novel Swine-Origin Influenza A (H1N1) Virus Investigation Team, 2009].

It appears that zoonotic infections with the Eurasian swFLUAVs cause a benign disease with mild influenza-like symptoms whereas infections with classical swine strains may lead to more serious symptoms. Few fatalities after infections with the latter viruses were reported [reviewed in Myers et al., 2007]. A recent study conducted in the United States revealed an increased risk of infection among pig farm workers, veterinarians and slaughterers [Myers et al., 2006]. Despite repeated isolation of Eurasian swFLUAVs from human specimens, the prevalence of zoonotic infections in Europe is largely unknown. The prevalence of antibodies directed against the Eurasian swFLUAVs in probands from Thuringia, Germany, with occupational exposure to pigs, was determined in this study. 


\section{MATERIAL AND METHODS}

\section{Experimental Design of the Study}

In order to determine the prevalence of antibodies against swine influenza viruses in the blood of professionals with occupational exposure to pigs (exposed study group), a two-step approach was chosen. Firstly, sera from pig farm workers, pig slaughterers/meat inspectors and veterinarians from Thuringia, Germany, were assayed by the hemagglutination-inhibition (HI) test against swFLUAVs of the subtypes H1N1, H1N2 and H3N2. These subtypes are circulating at present in the European pig population. The participants of the study group were selected at random. As a control, sera from a group of age- and gender-matched blood donors who had no known contact to pigs were included in the study (unexposed control group). Of each prevalent swFLUAV subtype, three strains were included in the HI test. Possible cross-reactions with seasonal influenza viruses were examined by inclusion of three recent human strains [A/New Caledonia/20/1999 (H1N1), A/Berlin/1/2003 (H3N2), A/BadenWürttemberg/20/2003 (H1N2)] in the HI assays. In addition, all sera were tested against A/Port Chalmers/1/1973 (H3N2) and A/Chile/1/1983 (H1N1). Finally, a NP-specific ELISA (NovaTec, Dietzenbach, Germany) and a HA-specific ELISA (Virotech, Rüsselsheim, Germany) were conducted to monitor influenza the history of each serum. In the second step, sera with geometric mean titers of hemagglutination-inhibiting antibodies $\geq 80$ and/or fourfold increase in HI titers against swine influenza viruses, were also assayed by the neutralisation test (NT) against porcine and human strains to confirm the HI results.

\section{Study Group and Controls}

The seroprevalence study was conducted from December, 2007 to April, 2009 in Thuringia, Germany. The study group (total n=118) included (i) 46 pig farmers, (ii) 50 slaughterers and meat inspectors who primarily processed pigs, (iii) 22 veterinarians caring for pig herds. A control group without pig contact was included comprising 118 blood donors from Thuringia. Control subjects were 
frequency-matched by gender and age ( $<40$ years, 40 to 49 years, $\geq 50$ years). Forty-six participants in each group were female and 72 were male (Table I). Each participant was interviewed to obtain information regarding age, work experience, average exposure to pigs per week, and influenza vaccination history. Blood sampling and test were conducted in compliance with the Declaration of Helsinki. The experiments were approved by the Ethics Committee of the Jena University Hospital (reference number 2092-08/07). Written informed consent was obtained from of each participant.

\section{Viruses}

The following nine viruses were used: (i) from the Federal Research Institute for Risk Assessment, Berlin, Germany: A/swine/Belzig/2/2001 (H1N1), (ii) from IDT Biologika GmbH, Dessau-Rosslau, Germany: A/swine/Haselünne/IDT2617/2003 (H1N1), A/swine/Bad Griesbach/IDT5604/2006 (H1N1), A/swine/Bakum/1832/2000 (H1N2), A/swine/Waltersdorf/IDT2527/2003 (H1N2), A/swine/Gudensberg/IDT2930/2004 (H1N2), A/swine/Bakum/IDT1769/2003 (H3N2), A/swine/Bissendorf/IDT1864/2003 (H3N2), A/swine/Herzlake/IDT5336/2006 (H3N2), A/Port Chalmers/1/1973 (H3N2), (iii) the Robert Koch Institute, Berlin, Germany: A/New Caledonia/20/1999 (H1N1), A/Baden Württemberg/20/2003 (H1N2), A/Berlin/1/2003 (H3N2), (iv) the Landesgesundheitsamt Niedersachsen, Hannover, Germany: A/Chile/1/1983 (H1N1). All porcine strains were sequenced completely to assure their membership to the Eurasian lineages of swFLUAVs. Three strains [A/swine/Haselünne/IDT2617/2003 (H1N1), A/swine/Bakum/1832/2000 (H1N2), A/swine/Bakum/1769/2003 (H3N2)] are components of a new trivalent swine influenza vaccine. The viruses were either passaged in embryonated hens eggs or in Madin Darby Canine Kidney (MDCK) cells (ATCC CCL-34). Cells were propageted in Eagle Minimum Essential medium (EMEM) supplemented with $10 \%(\mathrm{v} / \mathrm{v})$ fetal bovine serum, $100 \mathrm{units} / \mathrm{ml}$ penicillin, $100 \mu \mathrm{g} / \mathrm{ml}$ streptomycin, $2 \mathrm{mM}$ L-glutamine, $1.3 \%(\mathrm{v} / \mathrm{v})$ sodium bicarbonate. Virus titers were determined by the $50 \%$ tissue culture infectious dose ( TCID $\left._{50}\right)$ assay according to Reed and Munch. 


\section{Hemagglutination-Inhibition (HI) Assay}

For the HI assay, pretreatment of sera was carried out as follows: (i) pretreatment with neuraminidase (SIGMA, N-3001) 1:40 diluted with 0.9\% (w/v) sodium chloride for 14-18 hours at 37 ${ }^{\circ} \mathrm{C}$, (ii) addition of $1.5 \%(\mathrm{w} / \mathrm{v})$ sodium citrate and inactivation for $30 \mathrm{~min}$ at $56{ }^{\circ} \mathrm{C}$, (iii) adsorption of sera with red blood cells for one hour at $4-8{ }^{\circ} \mathrm{C}$. Serial twofold dilution of sera was carried out in microtiter plates. Standardised antigen (with a hemagglutination titer of 8 hemagglutinating units of each antigen investigated) was then added to $100 \mu \mathrm{l}$ serum dilution. The mixture was incubated at $20-25{ }^{\circ} \mathrm{C}$ for $45 \mathrm{~min}$ and a standardised solution $(0.5 \%)$ of red blood cells was added. The reaction was again incubated at $20-25{ }^{\circ} \mathrm{C}$ for $30 \mathrm{~min}$. Negative and positive controls as well as sera controls and red blood cell control were included. Finally, the HI titers (the highest dilution of serum that inhibited virusinduced hemagglutination) were recorded. HI assay was carried out three times on each virus, and the geometric mean HI titers were calculated. Chicken red blood cells were used for all influenza viruses except the recent human $\mathrm{H} 3 \mathrm{~N} 2$ strain A/Berlin/1/2003; for this strain turkey red blood cells were used. A high titer serum showed a HI titer $\geq 80$ and/or a fourfold increase when compared to the group-specific geometric mean titer. In addition, a box plot analysis was performed. High titer sera exceeded the interquartile range at least 1.5-fold (data not shown).

\section{Neutralisation Assay}

Twofold serial dilutions of sera were prepared for the neutralisation test, . All virus strains to be investigated were adjusted to $100 \mathrm{TCID}_{50} / 50 \mu$ l. Fifty microliters of these working dilutions of virus were mixed with $100 \mu \mathrm{l}$ of serum dilutions and incubated one hour at $37^{\circ} \mathrm{C}$. MDCK monolayers in microtiter plates were then infected with the neutralisation mixtures. Trypsin [porcine, gamma-irradiated (Sigma), final concentration 4 BAEE units/ml medium] was added to the medium and readded after 24 hours. After 48 hours of incubation $\left(37^{\circ} \mathrm{C}\right.$ and $\left.5 \% \mathrm{CO}_{2}\right)$, cells were fixed with $4 \%$ formalin $\left(4-8{ }^{\circ} \mathrm{C}\right)$ and stained with crystal violet. Finally the $\mathrm{ND}_{50}$ (highest dilution of serum which neutralised the virus strain) was calculated. The neutralisation assay was performed two times with each virus strain, and 
geometric mean neutralisation titers were calculated. Geometric mean neutralisation titers $\geq 1: 80$ were scored positive in order to obtain higher values of specificities.

\section{Influenza Virus-Specific ELISA}

Two commercial influenza virus-specific ELISAs were used to analyse the influenza history of the exposed study group and the control group. A nucleoprotein (NP) specific ELISA based on A/Texas/1/1977 (H3N2) and B/Hong Kong/5/1972 was obtained from NovaTec (Dietzenbach, Germany). An IgG-specific ELISA directed against the hemagglutinins of the 2006/07 season (A/Solomon Islands/03/06-like H1N1 and A/Wisconsin/67/05-like H3N2 viruses) was obtained from Virotech (Rüsselsheim, Germany). Both assays were conducted as described by the manufacturers. A serum was considered positive when the assay yielded values greater 11 ELISA units [ELISA unit of proband serum $=10 \mathrm{x}\left(\mathrm{OD}_{450}\right.$ proband serum $/ \mathrm{OD}_{450}$ cut-off control $\left.)\right]$. Sera yielding $<9$ ELISA units were considered negative; sera yielding 9.0-11.0 ELISA units were considered indeterminate.

\section{Statistical Analysis of Serological Data}

According to reported data [Myers et al., 2006] a seroprevalence of $10 \%$ to $20 \%$ was expected in the exposed subjects. For this pilot study, a stratified sampling of about 40 subjects selected at random per occupational subgroup was planned. A two-sided $95 \%$ confidence interval (CI) would extend $9 \%$ to $12 \%$ from the observed prevalence.

Data were displayed by geometric means and geometric standard deviations (GSD) as appropriate. Group-specific prevalences were estimated with exact 95\% CI assuming a binomial distribution. If the global $\chi^{2}$-test of homogeneity could be rejected for a subtype at alpha=0.05 seroprevalences of occupational subgroups were compared to controls subsequently. A p-value of $<0.05$ was considered to be statistically significant. SAS V0-2 and SPSS 15.0 were used for analysis. 


\section{RESULTS}

\section{Characteristics of the Study Group and Controls}

The study group (exposed) and the control group (unexposed) each consisted of 118 participants. The composition of the control group was chosen to match the study group in terms of gender and age (Table I). The ratio of male and female subjects was $72(61 \%)$ to $46(39 \%)$ in both groups. The mean age was 44.6 years $(\mathrm{SD}=10.7)$ in the exposed and 43.8 years $(\mathrm{SD}=11.8)$ in the unexposed subjects. Analysis of the questionaire revealed no significantly higher proportion of influenza vaccination in the control group. Sixty-five of 118 participants (55.1\%) of the control group vs. 52 of 118 participants (44.1\%) of the study group remembered at least one vaccination $\left(\mathrm{p}=0.059,1\right.$-sided $\chi^{2}$-test). One hundred and thirteen of 117 sera of the exposed group and 116 of 118 sera of the control group exhibited a previous influenza virus infection using a NP-specific ELISA. A HA-specific ELISA directed against virus strains of the $2006 / 2007$ season showed $48.7 \%$ positive sera of the exposed group and $50.1 \%$ of the control group. The results of the NP- and HA-specific ELISAs indicate that both groups were comparable regarding previous influenza virus infections (NP ELISA: $\mathrm{p}=0.402$, HA ELISA: $\mathrm{p}=0.744$ ).

\section{HI Assays}

HI assays were performed to identify sera with increased antibody titers to swFLUAVs. For each of the three swFLUAV subtypes, three strains were included in the HI assays (H1N1: A/swine/Belzig/2/2001, A/swine/Haselünne/IDT2617/2003, A/swine/Bad Griesbach/IDT5604/2006, H1N2: A/swine/Bakum/1832/2000, A/swine/Waltersdorf/IDT2527/2003, A/swine/Gudensberg/IDT2930/2004, H3N2: A/swine/Bakum/IDT1769/2003, A/swine/Bissendorf/IDT1864/2003, A/swine/Herzlake/IDT5336/2006). The geometric mean HI titers of the study group were 10.34 (GSD \pm 12.08$)$ for the H1N1 strains, $29.21(\mathrm{GSD} \pm 27.14)$ for the H1N2 strains and $24.68(\mathrm{GSD} \pm 33.14)$ for the $\mathrm{H} 3 \mathrm{~N} 2$ strains. Eighteen conspicuous proband sera of the exposed group (15.3\%) were identified (Table II), 16 of whom had HI titers $\geq 80$; two sera (S \#47, V \#10) were 
identified as outliers in the box plot (data not shown). Six to 12 months after sampling, those participants who had conspicuous sera were asked for a second blood sample. Thirteen of 18 participants agreed and the follow-up sera were re-investigated. All previous HI results were confirmed and the titers of the majority of the follow-up sera exceeded the previous HI titers (data not shown).

The geometric mean HI titers of the control group were 8.71 (GSD \pm 6.45$)$ (H1N1), 26.31 (GSD $\pm 23.26)(\mathrm{H} 1 \mathrm{~N} 2)$ and 23.98 (GSD \pm 23.23$)(\mathrm{H} 3 \mathrm{~N} 2)$. Twelve high titer sera were observed in the control group (Table II). Comparison of the HI results of the study group and the unexposed control group revealed no significant differences in the distribution of the HI titers (Table III) suggesting that this comparison may not be suited to distinguish swFLUAV infection and previous exposure to seasonal influenza. Therefore, neutralisation assays were performed with the 30 high titer sera compiled in Table II.

\section{Neutralisation Assays}

Neutralisation assays revealed that $17 / 18$ sera of the study group with raised HI antibody titers also had elevated neutralising antibody titers against at least one of the nine tested virus strains (Table II). A serum was scored positive for the respective strain if the reciprocal of the geometric mean titer was $\geq 80$. Only the swH1N2-positive result of slaughterer \#2 could not be confirmed by the NT. The NT titers against swH3N2 of sixteen sera exceeded those against huH3N2 indicating previous exposure to swH3N2. Likewise, 7 swH1N2 and 2 swH1N1 titers of the exposed group exceeded the titers of human reference strains. With the exception of C \#115, the high HI titers of the control sera could not be confirmed in the NT. Serum C \#115 also showed high HI and NT titers against the human H1 strains. One blood sample (S \#8) did not yield sufficient serum for the neutralisation tests with the human viruses.

\section{Prevalence}


Sixteen sera with HI and NT titers against swFLUAVs were identified in the exposed group (Table II). According to the stratified sampling, the seroprevalences of antibodies against the three swFLUAV subtypes were estimated for the three subgroups of exposed subjects and for the unexposed controls. The data are shown in Table IV.

The lowest prevalence of $0 \%$ in veterinarians, $0 \%$ in pig farmers and $4 \%$ in slaughterers was for $\mathrm{H} 1 \mathrm{~N} 1$. The prevalence for $\mathrm{H} 1 \mathrm{~N} 2$ ranged from $4.3 \%$ (pig farmers) to $9.1 \%$ (veterinarians) and those of $\mathrm{H} 3 \mathrm{~N} 2$ ranged from $8.7 \%$ (pig farmers) to $22.7 \%$ (veterinarians).

\section{DISCUSSION}

After their first appearence in Germany and Belgium in 1979, avian-like H1N1 swFLUAVs spread rapidly spread throughout Europe. Within 15 years, novel strains emerged after reassortment with human H3N2 and H1N1 viruses and replaced the classical swine H1N1 viruses. The earliest German humanlike H3N2 and H1N2 strains of the Eurasian lineages of swFLUAVs are documented 1982 and 2000, respectively [Schrader und Süß, 2003, 2004]. All three Eurasian lineages have the potential to cause zoonotic human infection and this has been demonstrated by the isolation of several virus strains from human specimens in recent years [Adiego Sancho et al., 2009; Claas et al. 1994; Gregory et al., 2001; Gregory et al., 2002; Rimmelzwaan et al. 2001; Schweiger et al. 2008]. As sporadic virus isolations from humans provide no indication on the actual number of zoonotic infections, the prevalence of antibodies against swFLUAVs in humans with occupational exposure to pigs in Thuringia, Germany was determined. The German Federal State of Thuringia has an area of 16,251 square kilometres and some 2.3 million inhabitants. With approximately 1,400 pig farms and 765,000 pigs (mean pig herd size: 544.1 pigs), it has a small pig population of $2.8 \%$ of German pigs compared to other German States such as Northrhine Westphalia (12,900 pig farms, 6,358,100 pigs, mean pig herd size: 493.6 pigs; $23.4 \%$ of German pigs) or Lower Saxony (14,300 pig farms, 8,201,700 pigs, mean pig herd size: 572.6 pigs; 
$30.2 \%$ of German pigs) (source: www.destatis.de, 3 May 2007). In the present study, the pig slaughterers/meat inspectors of four of eight Thuringian slaughterhouses were tested. These persons represent approximately $50 \%$ of the Thuringian pig slaughterers/meat inspectors. In addition, $5.1 \%$ of the Thuringian veterinarians caring for pig herds and approximately $0.9 \%$ of Thuringian pig farm workers involved in pig fattening were included. The participants of the exposed group were selected at random from the telephone directory and no evidence was found for biased sampling. Most participants of the study group stated numerous direct contacts to pigs (at least twice a week). Only veterinarian \#1 and pig farmer \#41 specified 1 contact per week. The control group was comparable to the study group regarding mean age, gender and influenza history but had no known exposure to pigs. Twelve subjects of this group exhibited high HI antibody titers (swH1N2: 7/12, swH3N2: 5/12). Only two of them (C \#88, C \#119) had a fourfold increase in the HI titer and only one control serum (C \#115) had both a 3-fold raised HI titer and a reciprocal geometric mean NT titer of 89.9. However, C \#115 serum also showed elevated HI and NT titers against human H1N1 and H1N2 viruses (Table II) suggesting that crossreactivity after previous exposure to seasonal virus may be a plausible explanation for its reaction with swH1N2. All high titer control sera which reacted with swH1N2 had also elevated antibody titers against human H1 strains (compare Table II). Two of the five control sera that reacted with swH3N2 had also high HI or NT titers against huH3N2 (Table II). Presuming random sampling, the proportions of sera scored positive against swFLUAVs were calculated. Dependent on profession and virus subtype different prevalences were observed (Table IV). However, the estimated prevalence of the swH1N1 subtype wase not significant since only two sera were positive against these antigens. In Germany, swH1N1 strains comprise approximately $10-15 \%$ of the swFLUAV isolates. In addition, swH1N1 causes diseases in the pig with milder symptoms and replicates at lower titers in the lungs compared to the swH1N2 and swH3N2 subtypes (Ralf Dürrwald, unpublished results). Therefore, exposure of the study group to swH1N1 viruses might have been lower in recent years than to the other swFLUAV subtypes. The swH1N2 and swH3N2 lineages have surface proteins derived from seasonal influenza viruses. Due 
to a better adaptation of these surface proteins to the human host, it can be assumed that zoonotic infections of humans are caused preferentially by the human-like swFLUAVes.

Zoonotic influenza virus infections appear to be not gender-specific; the observed bias of positive sera of male slaughterers is due to the imbalance of male and female employees working in this profession. All female employees of this proband subgroup worked as meat inspectors. Like the male meat inspectors, none of their sera reacted with swFLUAVs. This observation suggests that pig slaughtering itself is a risky activity whereas downstream processes such as meat inspection have a considerable lower risk of infection.

In the present study, virus neutralisation assays distinguished clearly between Eurasian swFLUAVs and those human seasonal influenza virus strains which were used for control (Table II). Some high titer study group sera (e.g., S \#21, S \#24, PF \#22, V \#10, V \#14, V \#18) showed little or no cross-reaction with the human control virus strains. Other study group sera (e.g. S \#22, PF \#16, PF \#18, V \#1) reacted with both porcine and human strains. This finding may be explained with repeated exposure to human and porcine viruses. An alternative explanation could be the assumption of significant cross-reaction. Some cross-reaction of the sera of control subjects with swine H3N2 triple reassortants was observed in a previous study conducted by Myers et al. [2006]. In the present study, however, conspicuous sera of the study group and the control group differ considerably indicating that cross-reaction is not a major problem. Only serum PF \#18 showed antibodies against swH1N2, swH3N2 and the three human strains suggesting cross-reactivity. This serum was negative for swH3N2 as the HI and NT titers against huH3N2 were considerably higher. Future studies should include more human reference strains to address this question in more detail.

Recent studies provided evidence that humans with occupational exposure to pigs have experienced zoonotic influenza virus infections [Myers et al. 2006; Shinde et al. 2009]. The present study extends these previous observations for Thuringian employees even though American and Eurasian swFLUAVs evolved from genetically distinct origins. The zoonotic potential of animal influenza viruses led to the recommendation that workers with close contact to pigs and poultry should receive the annual human 
influenza vaccine [Gray et al., 2007]. It was reasoned that professionals with exposure to pigs and poultry could serve as a human bridging population for both human-to-animal and animal-to-human infections [Gray et al., 2007]. Annual influenza vaccination would decrease the threat of double infections of humans and reduce the risk of transmission of human virus strains to the pig population. This minimises the risk of concomitant double infections of swine with human and porcine virus strains and would lead to lessened reassortments and a reduced risk of generation of novel strains with pandemic potential. In view of the special situation caused by the pandemic A/H1N1 2009 virus, this recommendation should be implemented.

\section{ACKNOWLEDGMENT}

We are indebted to Dr. Brunhilde Schweiger, Robert Koch Institute, Berlin, Germany, Dr. Rolf Heckler, Landesgesundheitsamt Niedersachsen, Hannover, Germany, and Dr. Jochen Süss, Federal Research Institute for Risk Assessment, Berlin, Germany, for the gift of strains. We further thank Dr. Karsten Donat, Tierseuchenkasse Thüringen, and Karin Siedhoff, Landestierärztekammer Thüringen. This study was supported in part by grants of the Interdisziplinäres Zentrum für Klinische Forschung (Jena University Hospital), the Paul-Ehrlich-Gesellschaft für Chemotherapie e.V. and the Deutsche Vereinigung zur Bekämpfung der Viruskrankheiten e.V. awarded to A.K.

\section{REFERENCES}

Adiego Sancho B, Omenaca Teres M, Martinez Cuenca S, Rodrigo Val P, Sanchez Villanueva P, Casas I, Pozo F, Perez Brena P. 2009. Human case of swine influenza A (H1N1), Aragon, Spain, November 2008. Eurosurveillance 14:1-2.

Brown IH, Chakraverty P, Harris PA, Alexander DJ. 1995. Disease outbreaks in pigs in Great Britain due to an influenza A virus of H1N2 subtype. Vet Rec 136:328-329. 
Castrucci MR, Donatelli I, Sidoli L, Barigazzi G, Kawaoka Y, Webster RG. 1993. Genetic reassortment between avian and human influenza A viruses in Italian pigs. Virology 193:503-506.

Centers for Disease Control and Prevention. 2009. Swine Influenza A (H1N1) infection in two children - Southern California, March - April 2009. Morb Mort Weekly Rep 58:400-402.

Chutinimitkul S, Thippamom N, Damrongwatanapokin S, Payungporn S, Thanawongnuwech R,

Amonsin A, Boonsuk P, Sreta D, Bunpong N, Tantilertcharoen R, Chamnanpood P, Parchariyanon S, Theamboonlers A, Poovorawan Y. 2008. Genetic characterization of H1N1, H1N2 and H3N2 swine influenza virus in Thailand. Arch Virol 153:1049-1056.

Claas ECJ, Kawaoka Y, De Jong JC, Masurel N, Webster RG. 1994. Infection of children with avianhuman reassortant influenza virus from pigs in Europe. Virology 204:453-457.

Gray GC, Trampel DW, Roth JA. 2007. Pandemic influenza planning: shouldn't swine and poultry workers be included? Vaccine 25:4376-4381.

Gregory V, Lim W, Cameron K, Bennett M, Marozin S, Klimov A, Hall H, Cox N, Hay A, Lin YP. 2001. Infection of a child in Hong Kong by an influenza A H3N2 virus closely related to viruses circulation in European pigs. J Gen Virol 82:1397-1406.

Gregory V, Bennett M, Thomas Y, Kaiser L, Wunderli W, Matter H, Hay A, Lin YP. 2003. Human infection by a swine influenza A (H1N1) virus in Switzerland. Arch Virol 148:793-802.

Kluska V, Macku M, Mensik J. 1961. Demonstration of antibodies against swine influenza viruses in man [in Czech]. Cesk Pediatr 16:408-414.

Komadina N, Roque V, Thawatsupha P, Rimando-Magalong J, Waicharoen S, Bomasang E, Sawanpanyalert P, Rivera M, Iannello P, Hur AC, Barr IG. 2007. Genetic analysis of two influenza A (H1) swine viruses isolated from humans in Thailand and the Philippines. Virus Genes 35:161165.

Myers KP, Olsen CW, Gray GC. 2007. Cases of swine influenza in humans: a review of the literature. Clin Infect Dis 44:1084-1088. 
Myers KP, Olsen CW, Setterquist SF, Capuano AW, Donham KJ, Thacker EL, Merchant JA, Gray GC. 2006. Are swine workers in the United States at increased risk of infection with zoonotic influenza virus? Clin Infect Dis 42:14-20.

Novel Swine-Origin Influenza A (H1N1) Virus Investigation Team. 2009. Emergence of a novel swineorigin influenza A (H1N1) virus in humans. N Engl J Med 360:2605-2615.

Olsen CW. 2002. The emergence of novel swine influenza viruses in North America. Virus Res 85:199_ 210.

Peiris M, Yu WC, Leung CW, Cheung CY, Ng WF, Ng TK, Chan KH, Lai ST, Lim WL, Yuen KY, Guan Y. 2004. Re-emergence of fatal human influenza A subtype H5N1 disease. Lancet 363:617619.

Pensaert M, Ottis K, Vandeputte J, Kaplan MM, Bachmann PA. 1981. Evidence for the natural transmission of influenza A virus from wild ducks to swine and its potential importance for man. Bull WHO 59:75-78.

Rimmelzwaan GF, de Jong JC, Bestebroer TM, van Loon AM, Claas ECJ, Fouchier RAM, Osterhaus ADME. 2001. Antigenic and genetic characterization of swine influenza A (H1N1) viruses isolated from pneumonia patients in the Netherlands. Virology 282:301-308.

Schrader C, Süss J. 2003. Genetic characterization of a porcine H1N2 influenza virus strain isolated in Germany. Intervirology 46:66-70.

Schrader C, Süss J. 2004. Molecular epidemiology of porcine H3N2 influenza A viruses isolated in Germany between 1982 and 2001. Intervirology 47:72-77.

Schweiger B, Heckler R, Biere B. 2008. Characterization of a porcine influenzavirus isolated from a human sample. In: Programme and Abstracts; Heidelberg; March 5-8, 2008; Abstract CLV2. Heidelberg: 18th Annual Meeting Gesellschaft für Virologie.

Shinde V, Bridges CB, Uyeki TM, Shu B, Balish A, Xu X, Lindstrom S, Gubareva LV, Deyde V, Garten RJ, Harris M, Gerber S, Vagasky S, Smith F, Pascoe N, Martin K, Dufficy D, Ritger K, Conover 


\author{
C, Quinlisk P, Klimov A, Bresee JS, Finelli L. 2009. Triple-reassortant swine infuenza A (H1) in \\ humans in the United States, 2005-2009. N Engl J Med 360:2616-2625. \\ Smith GJD, Vijaykrishna D, Bahl J, Lycett SJ, Worobey M, Pybus OG, Ma SK, Cheung CL, Raghwani \\ J, Bhatt S, Peiris JSM, Guan Y, Rambaut A. 2009. Origins and evolutionary genomics of the 2009 \\ swine-origin H1N1 influenza A epidemic. Nature 459:1122-1125. \\ Subbarao K, Klimow A, Katz J, Regnery H, Lim W, Hall H, Perdue M, Swayne D, Bender C, Huang J, \\ Hemphill M, Rowe T, Shaw M, Xu X, Fukuda K, Cox N. 1998. Characterization of an avian \\ influenza A (H5N1) virus isolated from a child with a fatal respiratory illness. Science 279:393- \\ 396.
}

Witte KK, Nienhoff H, Ernst H, Schmidt U, Prager D. 1981. The 1st appearance of swine influenza in pig herds in the Federal-Republic-of-Germany [in German]. Tierärztliche Umschau 36:591.

Zell R, Motzke S, Krumbholz A, Wutzler P, Herwig V, Dürrwald R. 2008. Novel reassortant of swine influenza H1N2 virus in Germany. J Gen Virol 89:271-276. 